\title{
VTOS Cross-Linked PDMS Membranes for Recovery of Ethanol from Aqueous Solution by Pervaporation
}

\author{
Jin Gu, ${ }^{1}$ Yunxiang Bai, ${ }^{1}$ Lin Zhang, ${ }^{2}$ Lirong Deng, ${ }^{1}$ Chunfang Zhang, \\ Yuping Sun, ${ }^{1}$ and Huanlin Chen ${ }^{2}$ \\ ${ }^{1}$ The Key Laboratory of Food Colloids and Biotechnology, Ministry of Education, School of Chemical and Material Engineering, \\ Jiangnan University, Wuxi 214122, China \\ ${ }^{2}$ Department of Chemical and Biochemical Engineering, Zhejiang University, Hangzhou 310027, China
}

Correspondence should be addressed to Yuping Sun; sunyp2003@yahoo.com.cn

Received 25 March 2013; Accepted 7 May 2013

Academic Editor: Hai-Yin Yu

Copyright (C) 2013 Jin Gu et al. This is an open access article distributed under the Creative Commons Attribution License, which permits unrestricted use, distribution, and reproduction in any medium, provided the original work is properly cited.

PDMS membranes were prepared by cross-linking with vinyltriethoxysilane (VTOS) on polyacrylonitrile (PAN) substrate to increase hydrophobicity and improve pervaporation (PV) performance. It was shown that the membranes had high ethanol permselectivity and flux. The effects of cross-linking temperature, the content of cross-linking agent, and feed temperature on PV performance of VTOS cross-linked PDMS membranes were investigated. For $6 \mathrm{wt} \%$ ethanol aqueous solution, the PDMS membrane had the high separation factor of 15.5 and total flux $573.3 \mathrm{~g} \cdot \mathrm{m}^{-2} \cdot \mathrm{h}^{-1}$, respectively, when the feed temperature was $40^{\circ} \mathrm{C}$, H-PDMS : VTOS : DBTDL $=1: 0.2: 0.02$ and cross-linking temperature was $80^{\circ} \mathrm{C}$.

\section{Introduction}

The production of ethanol as an alternative fossil fuel energy resource has been a subject of great interest so far, because of the uncertainty of petroleum supplies and the finite nature of fossil fuels. Moreover, from the viewpoint of global environmental protection, since the industrial uses of fossil resources go on releasing a large quantity of $\mathrm{CO}_{2}$ on earth which leads to increasing atmospheric temperature, the production of liquid fuel ethanol by fermentation from renewable biomass as a carbon source has been focused on. For removal of ethanol from water, other separation technologies such as distillation, liquid-liquid extraction, carbon adsorption, and air stripping are not applicable because of feed condition limitations, large volume of byproducts, or high cost of posttreatments. However, pervaporation can be applied without these limitations [1-4]. Pervaporation is a promising separation technique and is becoming recognized as an energy-efficient alternative to distillation and other separating methods for liquid mixtures, especially in cases that the traditional separation techniques are not efficient, such as separating of azeotropic mixtures [5, 6], isomeric components [7], and close-boiling point systems [8]. In addition, it can also offer advantages in energy savings. The success of PV for ethanol-water separation depends on the development of a membrane material that has high permeability, high permselectivity, and good film-forming properties. The polymers that have been used for ethanol permselective membranes include polydimethylsiloxane (PDMS) $[9,10]$, poly[1-(trimethylsilyl)1-propyne] (PTMSP) [11, 12], in which PTMSP suffers from unstable PV performance with time. So, PDMS membrane is the most important and promising polymer membrane at present, which has the highest permeability for gas or vapors [13] and a high separation performance for organic chemicals in water $[14,15]$ among all the industrialized polymers. However, PDMS membrane has an intrinsic disadvantage. PDMS has the properties of poor film-forming and the low selectivity. These disadvantages have been overcome by using cross-linked PDMS [9]. But the preparation of PDMS using tetraethylorthosilicate (TEOS) [16] as a crosslinking agent has insufficient hydrophobicity in traditional methods resulted in poor permeability. In this paper, PDMS membranes were prepared using the cross-linking agent vinyltriethoxysilane (VTOS) and used for separation of 


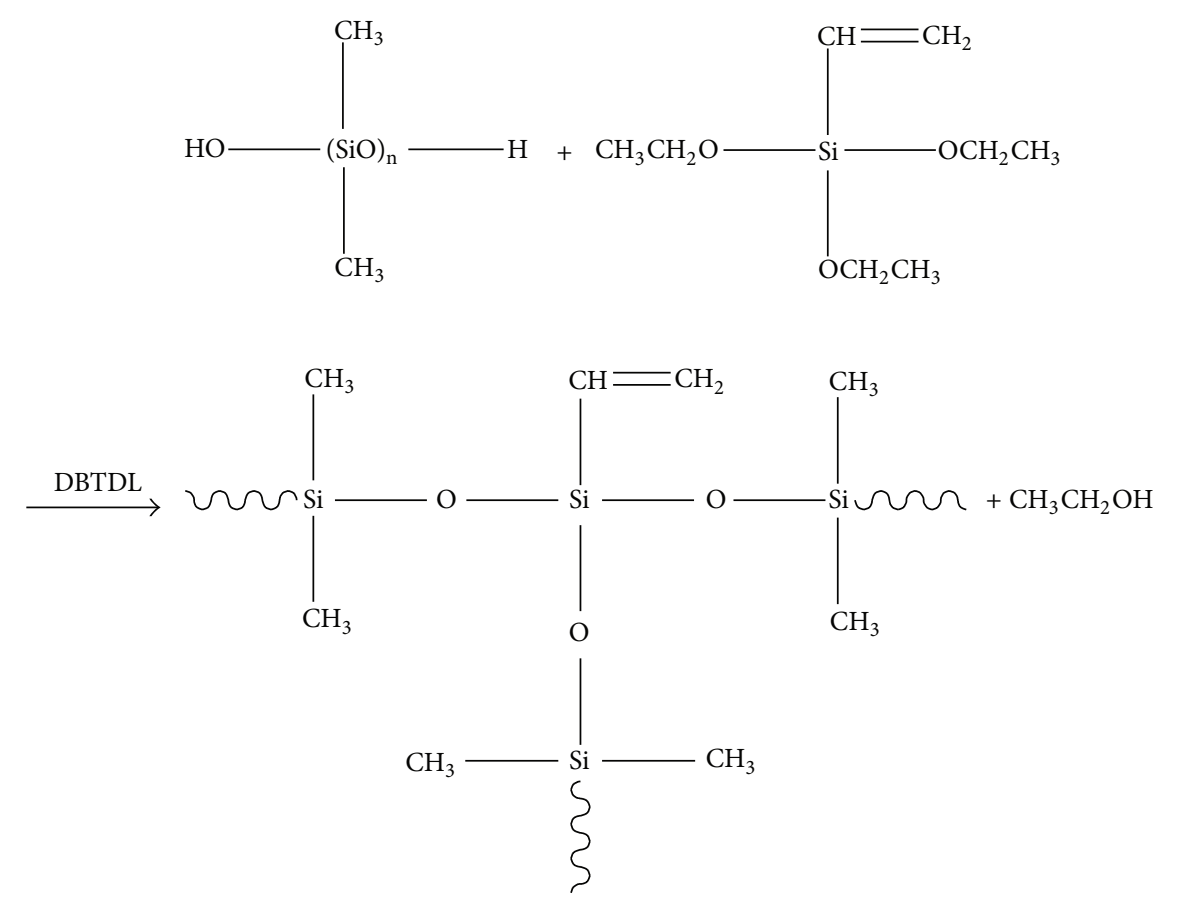

FIgURE 1: Preparation route of PDMS-VTOS.

ethanol/water mixtures. Due to the introduction of vinyl group, the hydrophobicity and the permeability of the PDMS membranes were increased.

The main objective of this study was to determine the effect of cross-linking temperature on the performance of PDMS membranes. Additionally, several of the parameters listed above were studied to assess their importance for the system.

\section{Experimental}

2.1. Materials. $\alpha, \omega$,-Dihydroxypolydimethylsiloxane $(\mathrm{H}-$ PDMS) with an average molecular weight of 5000 was purchased from Chenguang Research Institute of Chemical Industry, Chengdu, China. Tetraethylorthosilicate (TEOS), triethoxyvinylsilane (VTOS), dibutyltin dilaurate (DBTDL), $n$-hexane, and ethanol were obtained as analytical reagents from Shanghai Chemical Reagent Company, China. Polyacrylonitrile (PAN) ultrafiltration support membrane was purchased from Research and Development Center of Water Treatment Technology, Hangzhou, China.

2.2. Preparation of PDMS-VTOS/PAN Composite Membranes. H-PDMS, cross-linking agent VTOS, and catalyst DBTDL were mixed according to a 10/1/0.2 weight ratio in $n$-hexane. Prior to coating, PAN support was laid and spread out on the surface of water in a basin. Excess water on the PAN support surface was wiped off quickly with a filter paper. Directly afterwards, the PDMS solution was poured on the surface of support and the basin was put under a hood. The membrane system containing some cross-linked PDMS, after kept under ambient temperature for $2 \mathrm{~h}$, was introduced into a vacuum oven at $60^{\circ} \mathrm{C}$ for $4 \mathrm{~h}$ to complete the cross-linking. The chemical scheme was shown in Figure 1.

2.3. FTIR Measurement of PDMS-VTOS Membranes. The chemical structures of H-PDMS, PDMS-VTOS samples were confirmed by Fourier transform infrared (FTIR) using a VECTOR-22 type spectrometer. Samples for FTIR measurements were obtained by spreading a thin film of their solutions in $n$-hexane on a potassium bromide flake and evaporating the solvent under vacuum at room temperature.

2.4. Differential Scanning Calorimetry Measurements. DSC analyses over the temperature range from $-150^{\circ} \mathrm{C}$ to $25^{\circ} \mathrm{C}$ were conducted on a Perkin-Elmer DSC7 under nitrogen purge at a heating rate of $10^{\circ} \mathrm{C} / \mathrm{min}$. The DSC curves were obtained from a second heating cycle in order to remove heat history.

2.5. Static Contact Angle Measurement. Static contact angles for water of PDMS-VTOS/PAN composite membranes were measured by the sessile drop method using a Contact Angle Meter (OCA 20, Dataphysics, Germany) at $25^{\circ} \mathrm{C}$ and about $65 \%$ relative humidity. The volume of the water drop used was always $2 \mu \mathrm{L}$. All reported values were the average of at least eight measurements taken at different locations of the film surface and had a typical mean error of $\pm 1^{\circ}$.

2.6. Degree of Swelling Measurement. Dried PDMS-VTOS membranes without substrate were weighed and then immersed into an aqueous solution of $6 \mathrm{wt} \%$ ethanol in a sealed vessel at $30^{\circ} \mathrm{C}$ until equilibrium was reached. The membranes were carefully wiped by tissue papers to remove 
surface solvent and then weighted to measure the weight of the swollen membrane obtained. The equilibrium degree of swelling (DS) of the membranes was then determined from the following:

$$
\mathrm{DS}=\frac{m_{S}-m_{0}}{m_{0}} \times 100 \%,
$$

where $m_{0}$ and $m_{S}$ are the weights of dry and swollen membranes, respectively.

2.7. Pervaporation Measurement. PV experiments were conducted as previously reported [20]. The vacuum system of the downstream side was maintained at about $180 \mathrm{~Pa}$. The experiments were carried out in a continuous steady state, operated at constant temperature for ethanol/water mixtures. The flow rate was maintained at $2 \mathrm{~m} / \mathrm{s}$. Re number is about 10000. The permeation solution was collected in cold traps by condensation with liquid nitrogen. The composition of the permeation solution was determined using gas chromatography. The permeation flux $(J)$ and the separation factor $\left(\alpha_{\text {sep,ethanol/water }}\right)$ for all membranes were calculated according to the following equations:

$$
\begin{gathered}
J=\frac{\Delta g}{A \times \Delta t}, \\
\alpha_{\text {sep,ethanol } / \text { water }}=\frac{\left(P_{\text {ethanol }} / P_{\text {water }}\right)}{\left(F_{\text {ethanol }} / F_{\text {water }}\right)},
\end{gathered}
$$

where $\Delta g$ is the permeation weight collected in cold traps during the operation time $\Delta t, A$ is the membrane area $\left(18.1 \mathrm{~cm}^{2}\right), F_{\text {ethanol }}$ and $F_{\text {water }}$ are the weight fractions of ethanol and water in the feed side, and $P_{\text {ethanol }}$ and $P_{\text {water }}$ are the weight fractions in the permeate side, respectively.

\subsection{Determination of Sorption Selectivity and Diffusion Selec-} tivity. The sorption experiments were carried out as follows. A piece of dried PDMS-VTOS membrane without substrate with determined weight was immersed in anethanol/water mixture with $6 \mathrm{wt} \%$ ethanol in a sealed vessel at $30^{\circ} \mathrm{C}$ until equilibrium was reached. The swollen PDMS-VTOS membrane was wiped with a tissue paper quickly and placed into another container. The solution adsorbed in the swollen membrane was desorbed under reduced pressure and collected in a cold trap. The composition of the solution in the swollen membrane was obtained by measuring the ethanol concentration by gas chromatography in the collected solution. The sorption selectivity, $\alpha_{\text {sorp, ethanol/water, }}$, was determined by the ethanol composition in the membrane and the feed solution as expressed as follows:

$$
\alpha_{\text {sorp,ethanol } / \text { water }}=\frac{\left(M_{\text {ethanol }} / M_{\text {water }}\right)}{\left(F_{\text {ethanol }} / F_{\text {water }}\right)},
$$

where $F_{\text {ethanol }}$ and $F_{\text {water }}$ are the weight fractions of ethanol and water in the feed and $M_{\text {ethanol }}$ and $M_{\text {water }}$ are the weight fractions of ethanol and water in the swollen membrane, respectively. According to the solution-diffusion mechanism,

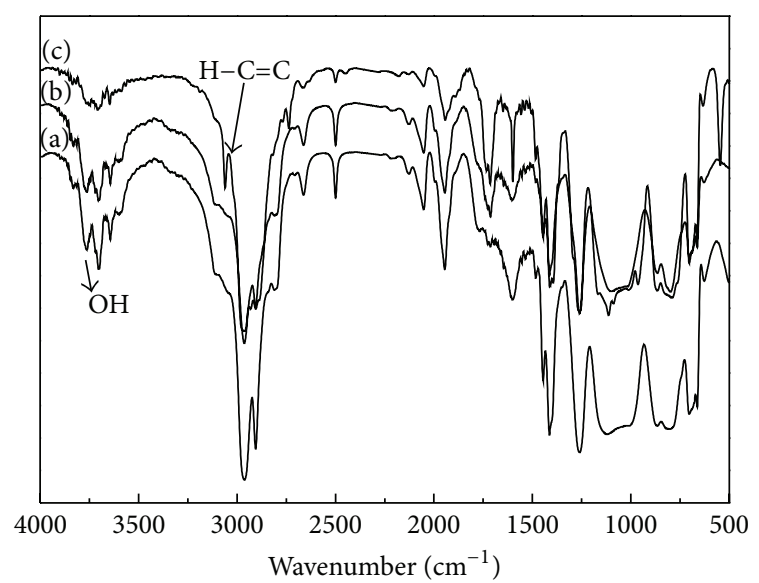

(a) H-PDMS

(b) $20^{\circ} \mathrm{C}$ PDMS-VTOS

(c) $80^{\circ} \mathrm{C}$ PDMS-VTOS

FIgURE 2: FTIR spectra of H-PDMS are $20^{\circ} \mathrm{C}$ PDMS-VTOS, $80^{\circ} \mathrm{C}$ PDMS-VTOS; $\mathrm{H}-\mathrm{PDMS}$ is PDMS with terminal $\mathrm{OH}$ groups, $20^{\circ} \mathrm{C}$ PDMS-VTOS is PDMS membrane prepared at $20^{\circ} \mathrm{C} ; 80^{\circ} \mathrm{C}$ PDMSVTOS is PDMS membrane prepared at $80^{\circ} \mathrm{C}$.

separation and permeation characteristics for organic liquid mixtures through polymeric dense membranes by PV are based on the solubility of the permeants into the polymer membrane (sorption process) and the diffusivity of the permeants in the polymer membrane (diffusion process). In general, the relation between them for ethanol/water mixture can be written as follows:

$$
\alpha_{\text {diff,ethanol } / \text { water }}=\frac{\alpha_{\text {sep,ethanol } / \text { water }}}{\alpha_{\text {sorp,ethanol } / \text { water }}} .
$$

\section{Results and Discussion}

\subsection{Characterization of Membranes}

3.1.1. FT-IR Spectra of Different Polymers. The hydrophobicity of $\mathrm{H}-\mathrm{PDMS}$ and cross-linked PDMS membrane at $80^{\circ} \mathrm{C}$ and $20^{\circ} \mathrm{C}$ are characterized by FTIR as shown in Figure 2. The peaks that occur at about $3100 \mathrm{~cm}^{-1}$ and $3744 \mathrm{~cm}^{-1}$ are assigned to the stretching vibrations of unsaturated carbonhydrogen bond and $\mathrm{Si}-\mathrm{OH}$. As can be seen in Figure 2, the intensities of peaks at $3744 \mathrm{~cm}^{-1}$ of $80^{\circ} \mathrm{C}$ PDMS samples are lower than those of H-PDMS and $20^{\circ} \mathrm{C}$ PDMS. Meanwhile, unsaturated carbon-hydrogen bond peak appears at $3100 \mathrm{~cm}^{-1}$ of cross-linked PDMS. The intensity of the peak from $80^{\circ} \mathrm{C}$ PDMS is larger than that from $20^{\circ} \mathrm{C}$ PDMS. These results may confirm that H-PDMS cross-linked with VTOS at $80^{\circ} \mathrm{C}$ becomes more hydrophobic.

3.1.2. Contact Angle of PDMS-VTOS Membranes. The membrane surface properties are also affected by cross-linking temperature and VTOS content. Table 1 and Figure 3 display the change of contact angle on the respective surfaces. The contact angle (CA) of PDMS-VTOS membranes 
TABLE 1: Contact angle for water of PDMS-VTOS membranes synthesized at different temperatures.

\begin{tabular}{lccccc}
\hline Cross-linking temperature $\left({ }^{\circ} \mathrm{C}\right)$ & 20 & 40 & 50 & 60 & 80 \\
Contact angle $\left({ }^{\circ}\right)$ & 64.5 & 101.9 & 106.2 & 107.7 & 108.3 \\
\hline
\end{tabular}

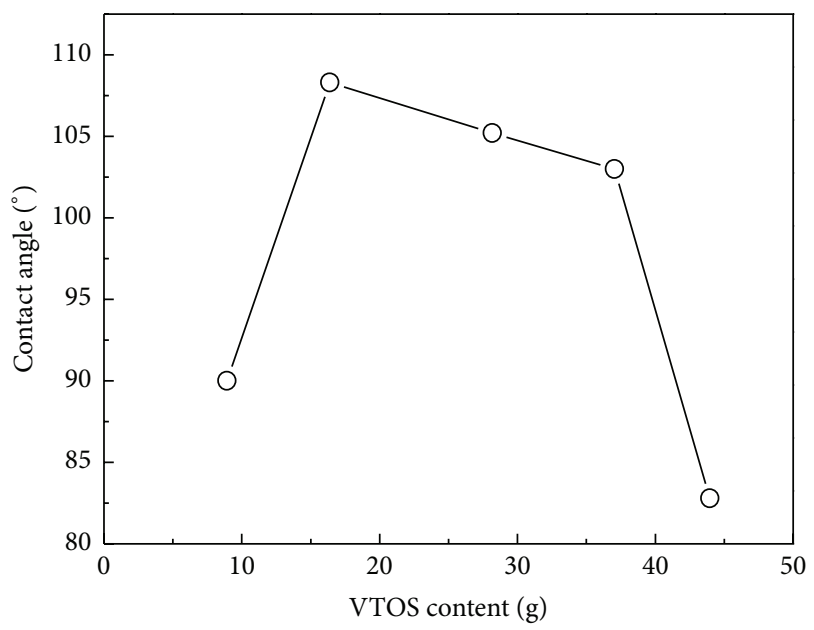

FIGURE 3: The effect of content of VTOS on contact angle of PDMSVTOS membranes (the cross-linking temperature: $80^{\circ} \mathrm{C}$ ).

increased with increasing cross-linking temperature. After cross-linking at $60^{\circ} \mathrm{C}$, the $\mathrm{CA}$ was $107.7^{\circ}$, and further increase of cross-linking temperature did not bring significant change in CA. This phenomenon is attributed to the fact that more hydroxyl groups were left in the membranes cross-linked under $60^{\circ} \mathrm{C}$ than those in the membranes cross-linked over $60^{\circ} \mathrm{C}$, as can be confirmed by the FT-IR spectra results.

However, the effects of VTOS content on surface properties show parabola tendency. As shown in Figure 3, the highest contact angle was achieved with $16.39 \mathrm{wt} \%$ of VTOS, which was the optimal content of the cross-linking agent. Too low VTOS content cross-linking is not enough to be preparation dense membrane which affects hydrophobicity of the membrane surface. Too much VTOS leads to some unreacted hydrophilic ethoxy group left in the membrane after the reaction of hydrolysis and condensation of VTOS, which made the hydrophobicity of PDMS-VTOS membrane decrease.

3.1.3. Measurements of Differential Scanning Calorimetry. Table 2 shows the DSC data of PDMS-VTOS cross-linked membranes with different cross-linking temperature. The $T_{g}$ has an insignificant fluctuation (from $-123.9^{\circ} \mathrm{C}$ to $-118.2^{\circ} \mathrm{C}$ ) with increasing cross-linking temperature. This result indicates that cross-linking temperature has no obvious effect on thermal property of the membrane. Meanwhile, it shows that membrane will not transform during pervaporation.

3.1.4. Swelling of PDMS Membrane in Alcohol/Water Mixtures. The results of swelling measurements of PDMS-VTOS in $6 \mathrm{wt} \%$ and $100 \mathrm{wt} \%$ ethanol/water binary mixtures at $40^{\circ} \mathrm{C}$
TABLE 2: Cross-linking effect on the glass transition temperatures $\left(T_{g}\right)$ of PDMS-VTOS membranes (the weight ratio of $\mathrm{H}$ PDMS : VTES : DBTDL is $1: 0.2: 0.02)$.

\begin{tabular}{lcccc}
\hline Cross-linking temperature $\left({ }^{\circ} \mathrm{C}\right)$ & 40 & 50 & 60 & 80 \\
$T_{g}\left({ }^{\circ} \mathrm{C}\right)$ & -119.3 & -123.9 & -118.7 & -118.2 \\
\hline
\end{tabular}

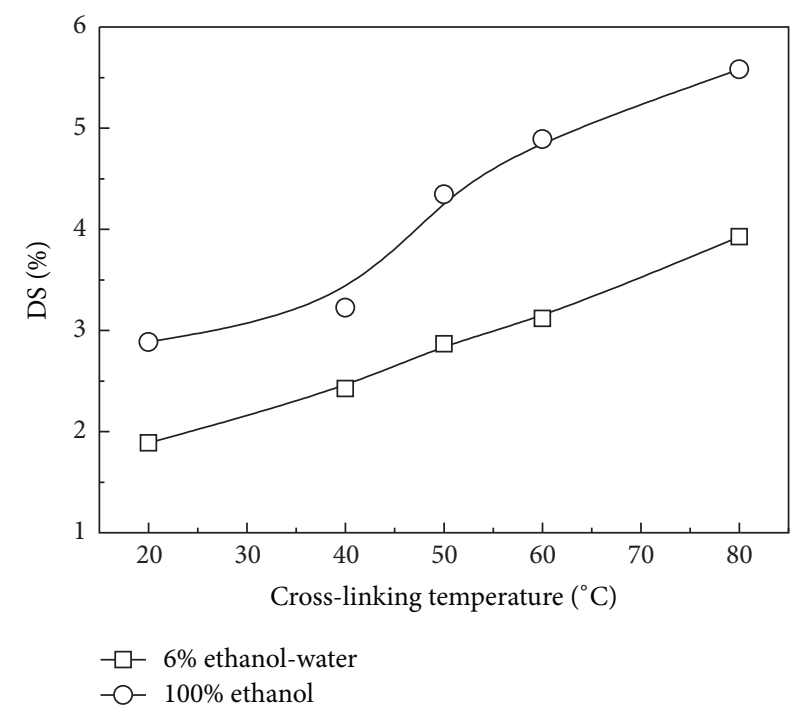

FIGURE 4: Effect of cross-linking temperature on the degree of swelling (DS) of PDMS-VTOS membrane immersed in aqueous solution of ethanol $6 \mathrm{wt} \%$ and $100 \mathrm{wt} \%$ ethanol content in the feed (temperature, $40^{\circ} \mathrm{C}$ ).

are presented in Figure 4. As can be seen, the DS of PDMSVTOS for mixtures increases separately with increasing crosslinking temperature. In addition, DS of PDMS in $100 \mathrm{wt} \%$ ethanol is higher than that of PDMS in $6 \mathrm{wt} \%$. These results indicate that VTOS cross-linked PDMS was swelling more in ethanol than in water.

\subsection{Pervaporation Performance}

3.2.1. Effect of Cross-Linking Temperature. Figure 5 shows the effects of cross-linking temperature on (a) ethanol in permeate and (b) the normalized permeation flux for an aqueous solution of $6 \mathrm{wt} \%$ ethanol through PDMS-VTOS membrane during PV with VTOS content of $16.39 \mathrm{wt} \%$. From Figure 5(a), the ethanol concentration in permeate through the PDMS-VTOS membranes was much higher than that in the feed in the studied cross-linking temperature range. These results suggest that PDMS-VTOS membranes have high ethanol permselectivity for an aqueous solution of $6 \mathrm{wt} \%$ ethanol. Meanwhile, both the separation factor and the ethanol concentration in permeate increased with increasing cross-linking temperature. From Figure 5(b), the ethanol and water flux through PDMS-VTOS membranes decreased with increasing cross-linking temperature.

In general, the PV performance for recovery of organic from its aqueous solution is based on the solubility of permeants into the polymer membrane (sorption process) 


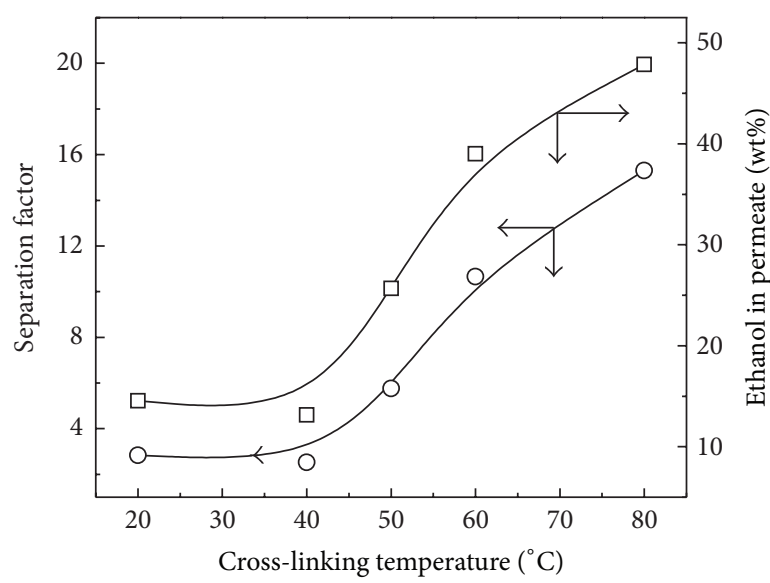

(a)

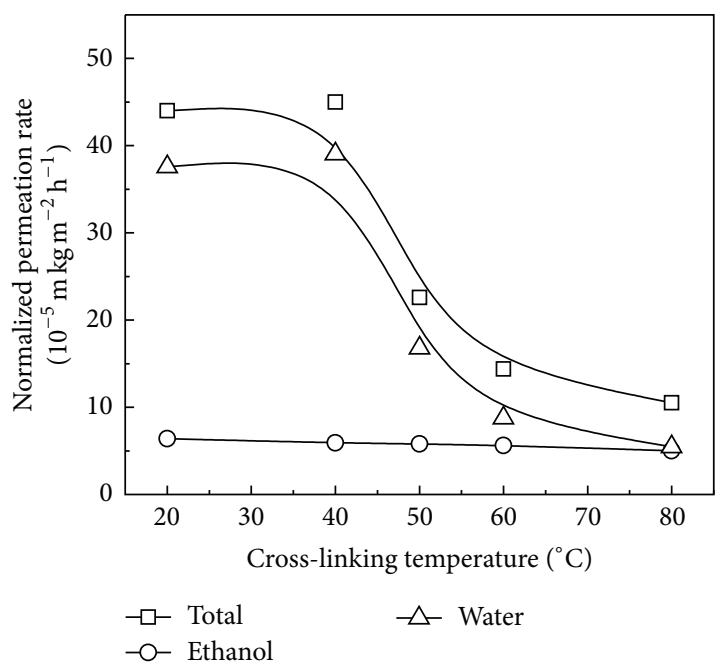

(b)

FIGURE 5: Effect of cross-linking temperature on (a) ethanol in permeate and (b) the normalized permeation flux for an aqueous solution of $6 \mathrm{wt} \%$ ethanol through PDMS-VTOS membrane during PV (operating temperature: $40^{\circ} \mathrm{C}$, the weight ratio of H-PDMS : VTOS : DBTDL is $1: 0.2: 0.02)$.

and the diffusivity of the permeants in the polymer membrane (diffusion process). The solubility and diffusivity of the permeants are significantly influenced by the chemical and physical structures of the polymer membranes. After crosslinked by VTOS, the PDMS-VTOS has better ethanol sorption selectivity with increasing cross-linking temperature. This result in Figure 6 is compared with those of the contact angle for water in Table 1; it is noted that the ethanol permselectivity strongly depends on the contact angle for water on the cross-linked membrane surface. Namely, the ethanol permselectivity of the cross-linked PDMS-VTOS membrane increased with an increase of the contact angle of water. The above results suggest that the ethanol permselectivity for an aqueous ethanol solution of the cross-linked PDMS-VTOS membranes is more significantly governed by the solubility of the permeants into the membrane than the diffusivity of the permeants in the membrane.

3.2.2. Effect of Cross-Linker VTOS Content. Curves of the pervaporation flux and the separation factor of PDMSVTOS cross-linked membranes versus VTOS contents are presented in Figure 7. As it can be seen, when VTOS content is from $8.93 \mathrm{wt} \%$ to $16.39 \mathrm{wt} \%$, the separation factor (a) upgrades but the pervaporation flux $(J)$ reduces with the increase of VTOS content. Obviously, the increase of VTOS content makes the structures of PDMS-VTOS crosslinked membranes compact and prevents the large ethanol molecules from passing the membrane. As it also can be seen, when VTOS content is from $16.39 \mathrm{wt} \%$ to $43.96 \mathrm{wt} \%$, the increase of VTOS content improves the pervaporation flux $(J)$ but decreases the separation factor $(\alpha)$. This phenomenon demonstrates that membranes with high VTOS content become more hydrophilic and relatively incompact structures. In this situation, both water and ethanol molecules can easily transmit the membranes, so the exaltation of

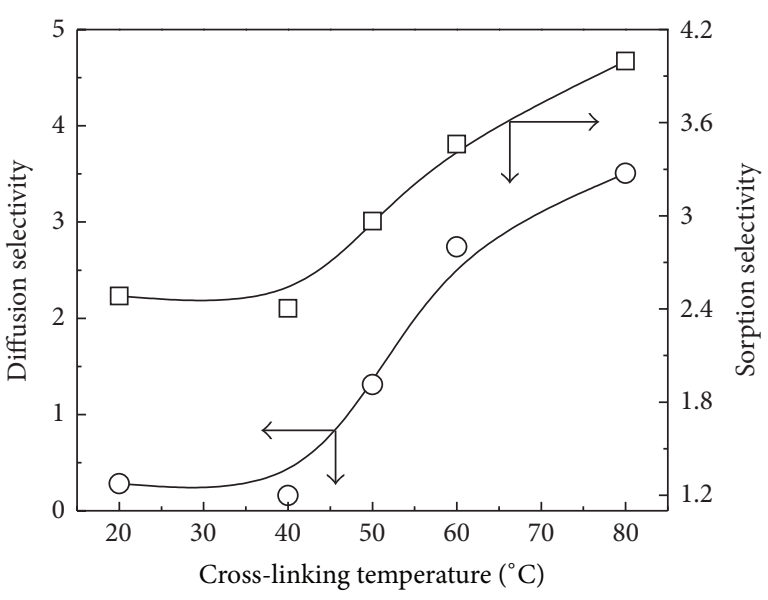

Figure 6: Effects of cross-linking temperature on the diffusion selectivity and sorption selectivity.

the pervaporation flux $(J)$ is accompanied by the decrease of the separation factor $(\alpha)$. Experimental data verify that when VTOS content is $16.39 \mathrm{wt} \%$, the separating properties of the cross-linked membranes are better; the separation factor $(\alpha)$ and the pervaporation flux $(J)$ of membranes can reach 15.3 and $573.3 \mathrm{~g} \cdot \mathrm{m}^{-2} \cdot \mathrm{h}^{-1}$, respectively.

3.2.3. Effect of Feed Temperature. Figure 8 presents the effect of temperature on pervaporation total flux of ethanol/water mixtures through cross-linked PDMS-VTOS membranes; the feed concentration is $6 \mathrm{wt} \%$ and VTOS content is $16.39 \mathrm{wt} \%$. An increase in feed temperature from $40^{\circ} \mathrm{C}$ to $80^{\circ} \mathrm{C}$ results in the increase in the total fluxes for the membranes. This is due to the fact that, during pervaporation, permeating 


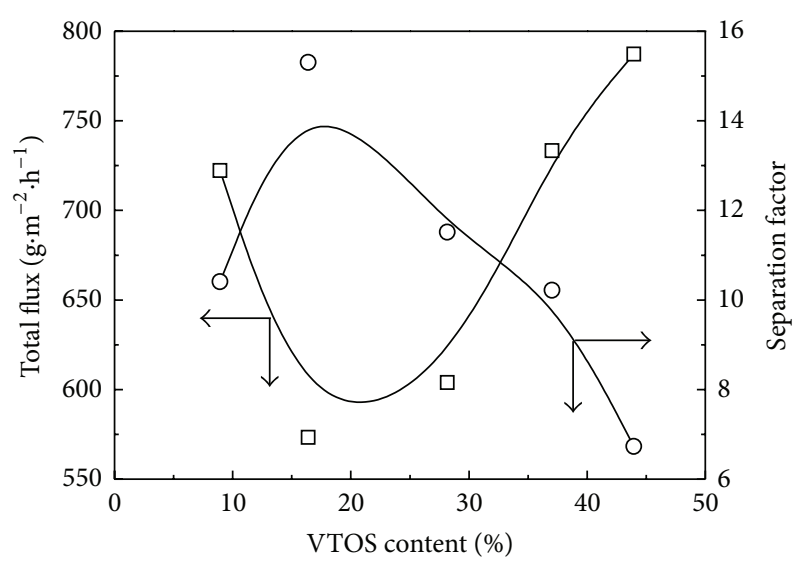

FIGURE 7: The effect of VTOS content on pervaporation properties of PDMS-VTOS membrane (feed concentration is $6 \mathrm{wt} \%$, the crosslinking temperature is $80^{\circ} \mathrm{C}$, and the $\mathrm{PV}$ temperature is $60^{\circ} \mathrm{C}$ ).

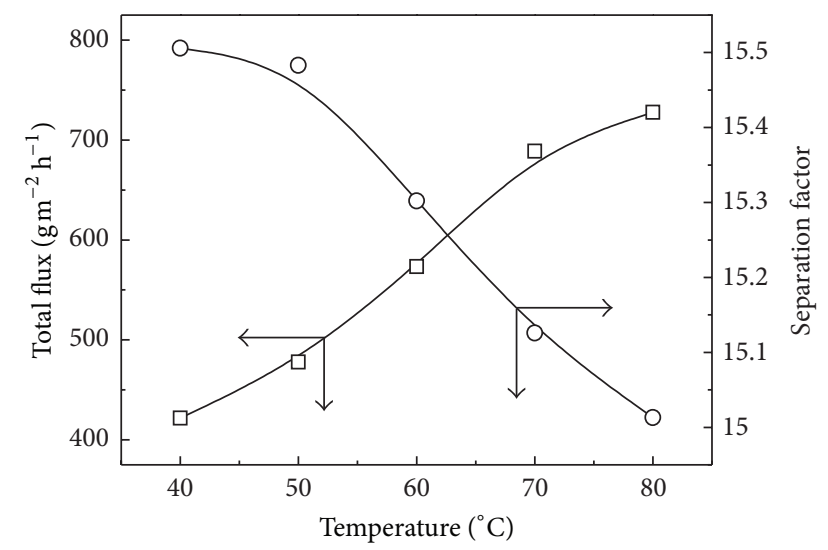

FIGURE 8: Feed temperature effect on PV performance of PDMSVTOS membrane feed concentration, $6 \mathrm{wt} \%$, the weight ratio of $\mathrm{H}-$ PDMS: VTOS:DBTDL is $1: 0.2: 0.02$, the cross-linking temperature is $80^{\circ} \mathrm{C}$.

molecules diffuse easily through free volumes of the membrane which is produced by thermal motions of polymer chains. Frequency and amplitude of polymer jumping chains increase as temperature increases. Thus, diffusion rate of individual permeating molecules increases leading to high permeation fluxes at higher temperatures. The separation factor for ethanol decreases with increasing temperature. This is a common phenomenon in a pervaporation process and can be explained by two theories. One claimed that a water molecular is much smaller than an ethanol molecular, so with the increase of operating temperature, the more flexible of polymer chains allow more water permeate through the membrane than ethanol, which leads to the reduction of separation factor. The other theory says that water cluster come into being on the feed side of a hydrophobic membrane. And the size of water cluster becomes more dominant at a lower temperature than at a higher temperature [21]. Therefore, the diffusivity of water will be restraint in a membrane at a lower temperature.

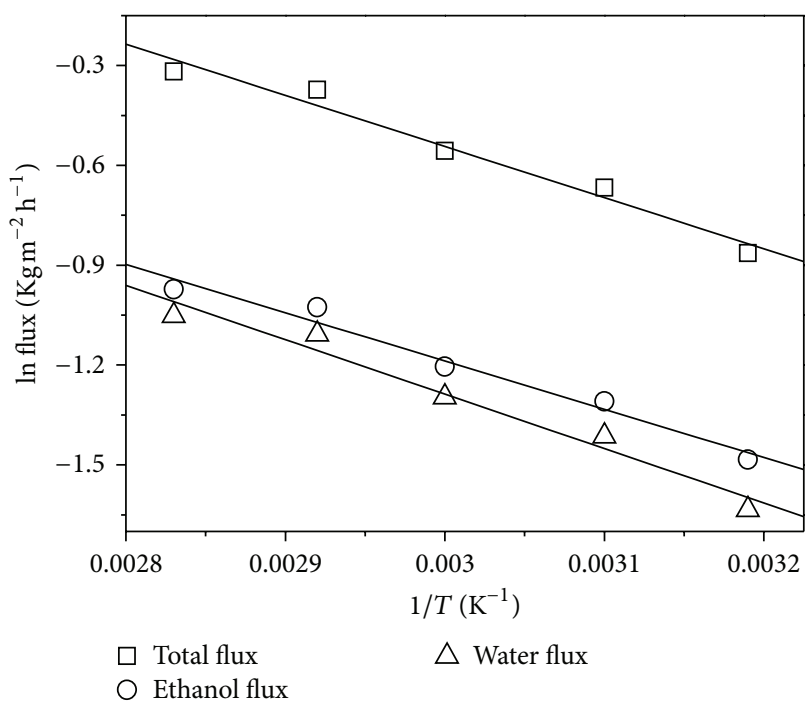

FIGURE 9: Arrhenius plots of the PDMS-VTOS membrane.

To get a deeper view of the relationships between temperature and permeation flux, the Arrhenius type equation was applied by $J=J_{0} \exp \left(-E_{p} / R T\right) . E_{p}$ is apparent activation energy for permeation, $J_{0}$ the permeation rate constant, $R$ the molar gas constant, and $T$ is the temperature in Kelvin. The $E_{p}$ values are $12.060 \mathrm{~kJ} / \mathrm{mol}$ and $13.596 \mathrm{~kJ} / \mathrm{mol}$ for ethanol and water, respectively, which are determined from the $\ln J$ versus $1 / T$ plots (Figure 9). The larger permeation activation energy of water implies that water permeation flux is more sensitive to increased temperature compared to that of ethanol permeation flux.

3.2.4. Comparing of Pervaporation Performance. Pervaporation performance in some previous studies and our study is listed in Table 3. As can be seen, the PDMS-VTOS membrane prepared in this research showed higher separation and lower permeation flux than those PDMS membranes cross-linked with TAOS reported for pervaporation removal of ethanol from dilute aqueous solution. The higher separation factor of PDMS-VTOS membranes can be attributed to two factors. One is a more hydrophobic nature of VTOS than TAOS and the other is that PDMS-VTOS membranes possess a higher cross-linking density than PDMS-TAOS membranes, because PDMS-VTOS membranes with a high separation factor were cross-linked at a higher temperature of $80^{\circ} \mathrm{C}$, which was usually performed at $60^{\circ} \mathrm{C}$. However, a higher cross-linking density is not favored for a permeation flux. That is why the total flux of PDMS-VTOS membranes is relatively lower than that of PDMS-TAOS membranes.

\section{Conclusions}

Cross-linked PDMS-PAN membranes using VTOS were prepared. The effects of parameters on the preparation and pervaporation performance were investigated. It was found that cross-linked PDMS-VTOS membranes had better hydrophobic when H-PDMS: VTOS: DBTDL $=1: 0.2: 0.02$, 
TABLE 3: Pervaporation performance of different PDMS-VTOS using cross-linking agent.

\begin{tabular}{lccc}
\hline Cross-linking agent & $\begin{array}{c}\text { Total flux } \\
\left(\mathrm{g} \cdot \mathrm{m}^{-2} \cdot \mathrm{h}^{-1}\right)\end{array}$ & Separation factor & Reference \\
\hline TAOS & 1140 & 9.3 & {$[17]$} \\
TAOS & 1300 & 8.3 & {$[18]$} \\
TAOS & 750 & 2.7 & {$[19]$} \\
VTOS & 573 & 15.3 & This work \\
\hline
\end{tabular}

cross-linking temperature is $80^{\circ} \mathrm{C}$. Meanwhile, PDMS-VTOS membranes have much higher separation factor than PDMSTAOS membranes reported in the literatures. Though the ethanol flux of PDMS-VTOS membranes are not so remarkable, it is also acceptable.

\section{Disclosure}

Shanghai Chemical Reagent Company and Research and Development Center of Water Treatment Technology are two companies from which we purchased chemical reagents.

\section{Conflict of Interests}

The authors declare that they have no conflict of interests.

\section{Acknowledgments}

The authors acknowledge the financial supports for this work from Natural Science Foundation of China (21106053), the Fundamental Research Funds for the Central Universities (JUSRP311A01), and the Industry-Academia Cooperation Innovation Fund Projects of Jiangsu Province (BY2012058).

\section{References}

[1] H. J. Kim, S. S. Nah, and B. R. Min, "A new technique for preparation of PDMS pervaporation membrane for VOC removal," Advances in Environmental Research, vol. 6, no. 3, pp. 255-264, 2002.

[2] D. J. O'Brien, L. H. Roth, and A. J. McAloon, "Ethanol production by continuous fermentation-pervaporation: a preliminary economic analysis," Journal of Membrane Science, vol. 166, no. 1-2, pp. 105-111, 2000.

[3] M. Di Luccio, C. P. Borges, and T. L. M. Alves, "Economic analysis of ethanol fructose production by selective fermentation coupled to pervaporation: effect of membrane costs on process economics," Desalination, vol. 147, no. 1-3, pp. 161-166, 2002.

[4] L. M. Vane, "A review of pervaporation for product recovery from biomass fermentation processes," Journal of Chemical Technology and Biotechnology, vol. 80, no. 6, pp. 603-629, 2005.

[5] M. Peng, L. M. Vane, and S. X. Liu, "Recent advances in VOCs removal from water by pervaporation," Journal of Hazardous Materials, vol. 98, no. 1-3, pp. 69-90, 2003.

[6] R. Psaume, P. Aptel, Y. Aurelle, J. C. Mora, and J. L. Bersillon, "Pervaporation: importance of concentration polarization in the extraction of trace organics from water," Journal of Membrane Science, vol. 36, pp. 373-384, 1988.
[7] H. L. Chen, L. G. Wu, J. Tan, and C. L. Zhu, "PVA membrane filled $\beta$-cyclodextrin for separation of isomeric xylenes by pervaporation," Chemical Engineering Journal, vol. 78, no. 2-3, pp. 159-164, 2000.

[8] I. Blume, J. G. Wijmans, and R. W. Baker, "The separation of dissolved organics from water by pervaporation," Journal of Membrane Science, vol. 49, no. 3, pp. 253-286, 1990.

[9] S. Takegami, H. Yamada, and S. Tsujii, "Pervaporation of ethanol/water mixtures using novel hydrophobic membranes containing polydimethylsiloxane," Journal of Membrane Science, vol. 75, no. 1-2, pp. 93-105, 1992.

[10] J. M. Molina, G. Vatai, and E. Bekassy-Molnar, "Comparison of pervaporation of different alcohols from water on CMG-OM010 and 1060-SULZER membranes," Desalination, vol. 149, no. 1-3, pp. 89-94, 2002.

[11] J. A. González-Marcos, C. López-Dehesa, and J. R. GonzálezVelasco, "Effect of operation conditions in the pervaporation of ethanol-water mixtures with poly(1-trimethylsilyl-1-propyne) membranes," Journal of Applied Polymer Science, vol. 94, no. 4, pp. 1395-1403, 2004.

[12] T. Masuda, M. Takatsuka, B. Z. Tang, and T. Higashimura, "Pervaporation of organic liquid-water mixtures through substituted polyacetylene membranes," Journal of Membrane Science, vol. 49, no. 1, pp. 69-83, 1990.

[13] S. A. Stern, Y. Mi, H. Yamamoto, and A. K. S. Clair, "Structure/permeability relationships of polyimide membranes. Applications to the separation of gas mixtures," Journal of Polymer Science B, vol. 27, no. 9, pp. 1887-1909, 1989.

[14] T. Miyata, Y. Nakanishi, and T. Uragami, "Ethanol permselectivity of poly(dimethylsiloxane) membranes controlled by simple surface modifications using polymer additives," Macromolecules, vol. 30, no. 18, pp. 5563-5565, 1997.

[15] T. Miyata, J. I. Higuchi, H. Okuno, and T. Uragami, "Preparation of polydimethylsiloxane/polystyrene interpenetrating polymer network membranes and permeation of aqueous ethanol solutions through the membranes by pervaporation," Journal of Applied Polymer Science, vol. 61, no. 8, pp. 1315-1324, 1996.

[16] F. J. Xiangli, W. Wei, Y. W. Chen, W. Q. Jin, and N. P. Xu, "Optimization of preparation conditions for polydimethylsiloxane (PDMS)/ceramic composite pervaporation membranes using response surface methodology," Journal of Membrane Science, vol. 311, no. 1-2, pp. 23-33, 2008.

[17] Y. Luo, S. J. Tan, H. Wang et al., "PPMS composite membranes for the concentration of organics from aqueous solutions by pervaporation," Chemical Engineering Journal, vol. 137, no. 3, pp. 496-502, 2008.

[18] L. Li, S. J. Tan, Z. Xiao, L. Pu, and Z. Zhang, "Composite PDMS membrane with high flux for the separation of organics from water by pervaporation," Journal of Membrane Science, vol. 243, no. 1-2, pp. 177-187, 2004.

[19] T. Mohammadi, A. Aroujalian, and A. Bakhshi, "Pervaporation of dilute alcoholic mixtures using PDMS membrane," Chemical Engineering Science, vol. 60, no. 7, pp. 1875-1880, 2005.

[20] J. Gu, X. Shi, Y. X. Bai, H. M. Zhang, L. Zhang, and H. Huang, "Silicalite-filled polyether-block-amides membranes for recovering ethanol from aqueous solution by pervaporation," Chemical Engineering and Technology, vol. 32, no. 1, pp. 155-160, 2009.

[21] Y. W. Huang, J. W. Fu, Y. Pan, X. B. Huang, and X. Z. Tang, "Pervaporation of ethanol aqueous solution by polyphosphazene membranes: effect of pendant groups," Separation and Purification Technology, vol. 66, no. 3, pp. 504-509, 2009. 

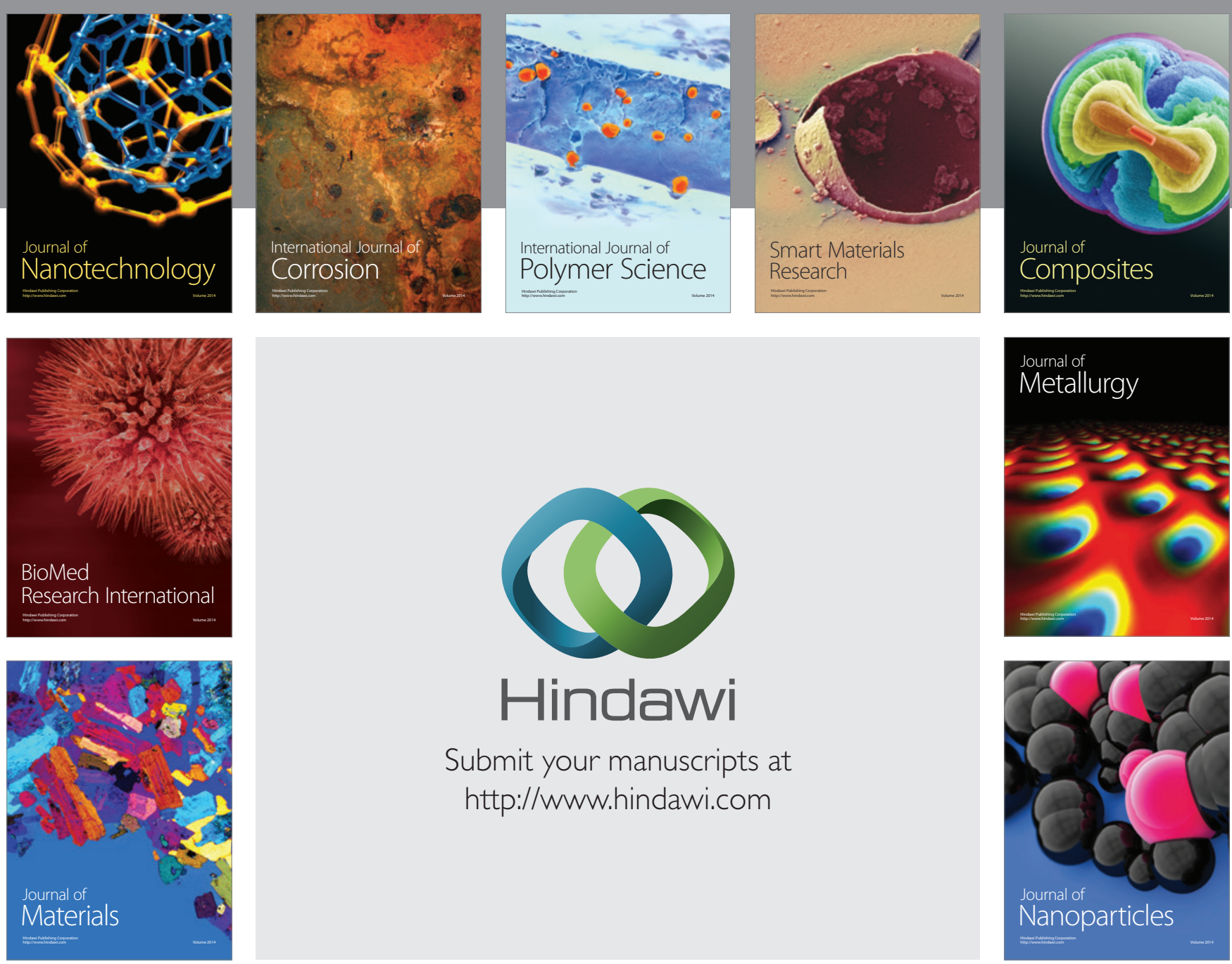

Submit your manuscripts at http://www.hindawi.com
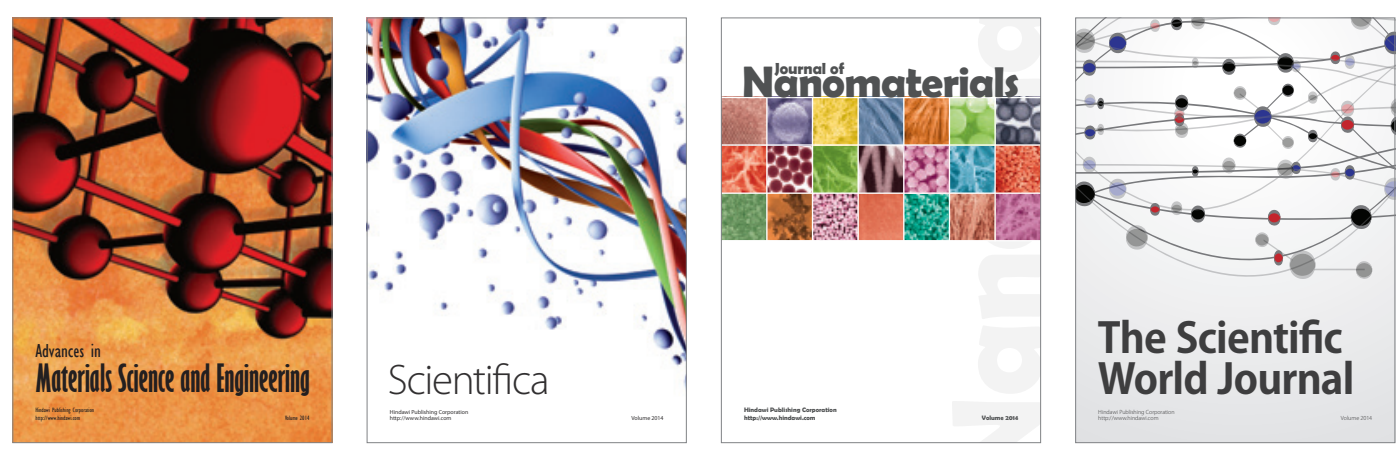

\section{The Scientific World Journal}
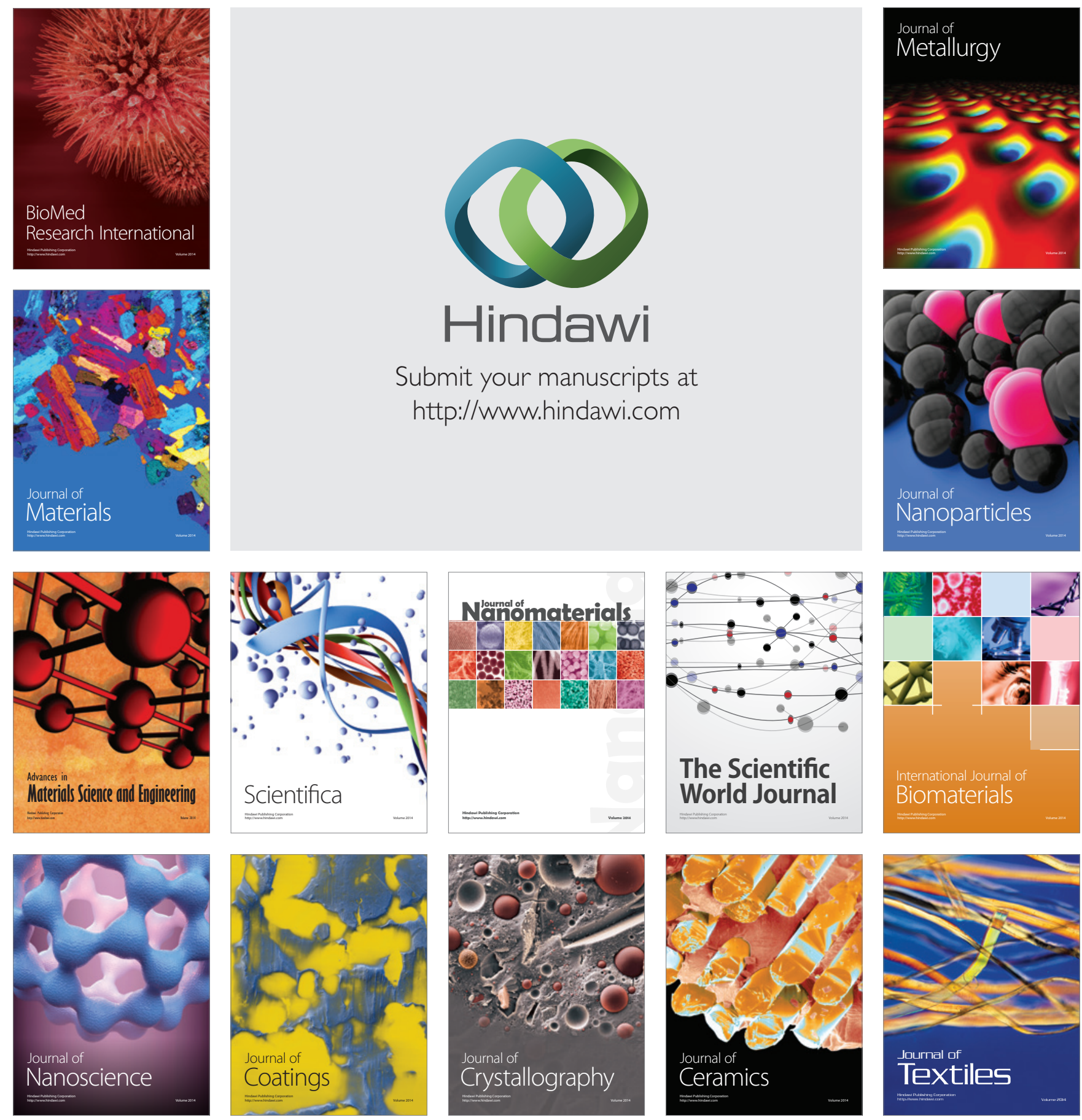